\title{
Selection and evaluation of e-commerce enterprises logistics operation models based on F-AHP method
}

\author{
Zhouxiang Guo ${ }^{1,}$, Xifu Wang 2,b \\ School of Traffic and Transportation, Beijing Jiaotong University, Beijing, 100044, China \\ a14120771@bjtu.edu.cn, ${ }^{\mathrm{a} x f w a n g 1 @ b j t u . e d u . c n}$
}

Keywords: E-commerce; Logistics operation model; Fuzzy Analytical Hierarchy Process

Abstract. This paper divides e-commerce enterprises logistics operation models into three forms: completely Self-built logistics, completely outsourcing and logistics alliance. Beginning from the logistics features of e-commerce enterprise, this paper established comprehensive evaluation index systems, and use Fuzzy Analytical Hierarchy Process to evaluate and choose the appropriate logistics operation model.

\section{Introduction}

The rapid expansion of e-commerce industry market size gives our country's modern logistics market a golden opportunity of development, but it also has brought the huge impact. How to use appropriate logistics mode to solve the problems of e-commerce enterprise logistics can be one of the key based on which e-commerce enterprises make the logistics decisions.

Logistics and e-commerce experts abroad already have a lot of research on e-commerce distribution. There is the famous traditional decision method, Ballow's two-dimensional decision method and Satty's analytic hierarchy process (AHP) ${ }^{[1]}$. In the "Global Logistics Management" ${ }^{[2]}$, Kent N.G Gourdin put forward the electronic commerce logistics cost, service quality selection model. Oliver Williamson ${ }^{[3]}$ use transaction cost theory to choose the right logistics operation mode. The use of appropriate logistics operation mode can make the enterprise reduce operating costs and improve logistics distribution service quality, improve their market competitiveness.

\section{E-commerce enterprise logistics operation mode analysis}

Viewed from e-commerce development at home and abroad, e-commerce enterprises are continuously exploring and trying to search for the appropriate operation model. At present, E-commerce enterprises mainly give priority to self-conducting logistics mode and third party logistics mode. Logistics alliance which developed based on aforementioned two logistics mode is also be adopted in some time.

The logistics operation processes of these three logistics modes are shown in figure 1. Fig.1(a) shows process of self-conducting logistics mode. Fig.1(b) shows process of third party logistics mode. Fig.1(c) shows process of logistics alliance mode.

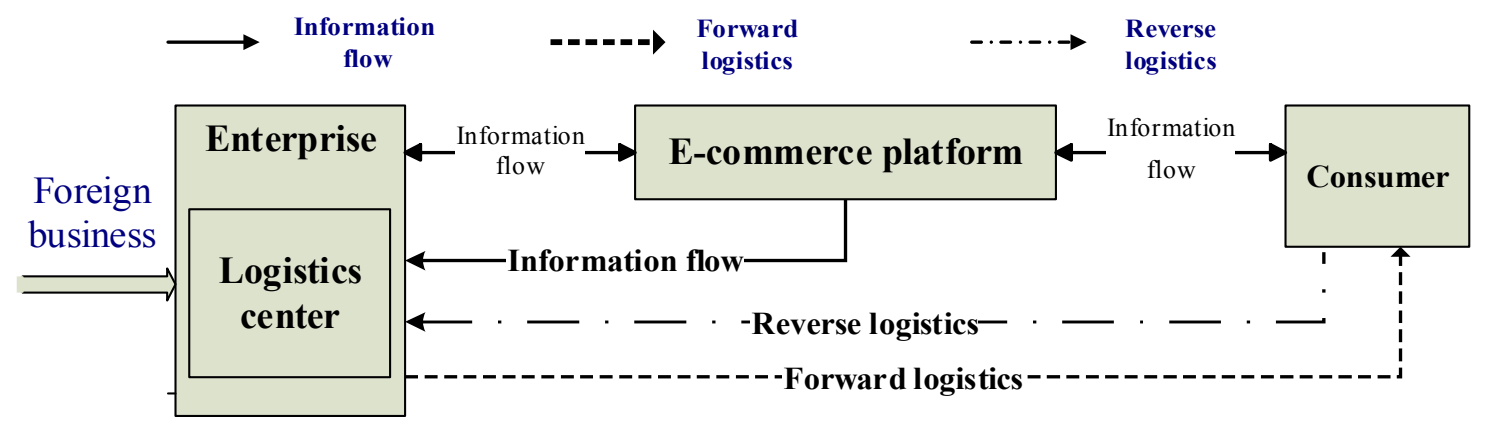

(a) 


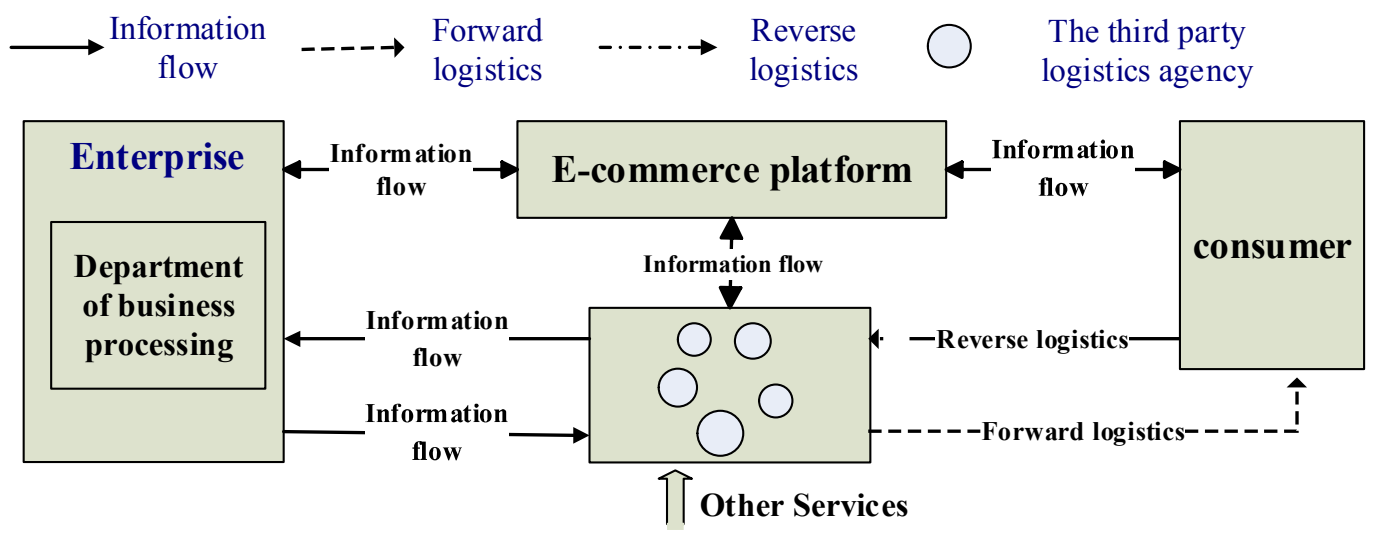

(b)

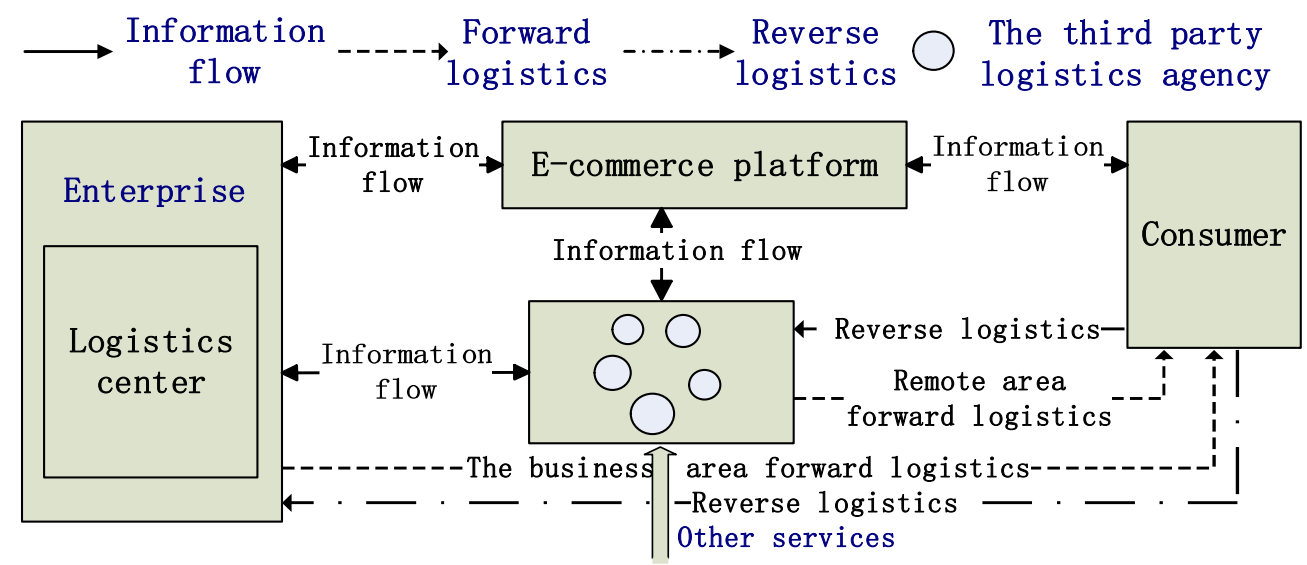

(c)

Fig.1 The logistics operation processes of these three logistics modes

\section{Logistics operation model evaluation index hierarchy}

It's a complex problem for e-commerce enterprises to choose logistics operation mode. Enterprises requires a combination of various factors taken into account, determine the logistics operation mode evaluation index, and establish evaluation index hierarchy. When determining the evaluation index of logistics operation mode, the object of study is not only limited to the electronic commerce enterprise itself. It also includes the third party logistics development level.

Considering the advantages and disadvantages of three kinds of logistics operation mode, logistics operation mode for the final evaluation index includes five aspects, 16 indicators, as shown in Fig2. 


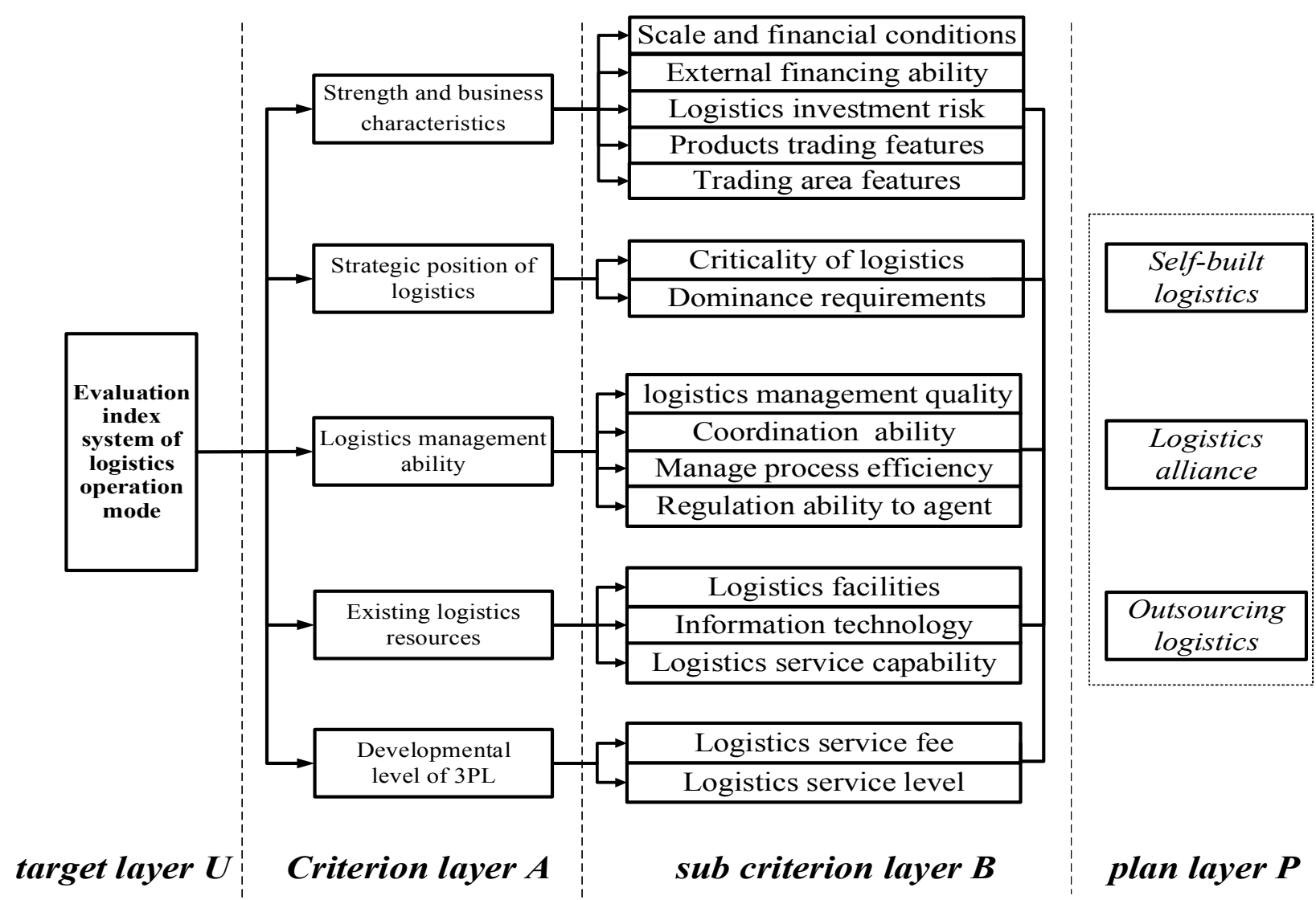

Fig.2 Logistics operation model evaluation index hierarchy structure

This article use Fuzzy analytic hierarchy process (FAHP) to evaluate and choose the right electronic business logistics modes as the reason that evaluation index system has distinct gradation and some data and indexes are difficult to measure and obtain.

\section{Designs of evaluation method based on F-AHP}

According to the logistics operation model evaluation index hierarchy structure established in Fig.1, we apply F-AHP method to selection and evaluation. The specific process is as followed:

Step 1: Determine the evaluation index and evaluation scheme sets

We can divide the indicator set into five secondary index set according to the property $U=\left\{U_{1}, U_{2}, U_{3}, U_{4}, U_{5}\right\}$, include $U_{1}$ Strength and business characteristics, $U_{2}$ Strategic position of logistics , $U_{3}$ Logistics management ability, $U_{4}$ Existing logistics resources, $U_{5}$ Developmental level of 3PL. Each secondary index can be further divided into several third class indexes $U_{i}=\left\{U_{i 1}, U_{i 2}, \cdots, U_{i j}\right\}, i=1,2,3,4,5 ; j=1,2, \ldots, f$ ( $f$ is fluctuant).

Evaluation scheme sets $M=\left\{M_{1}, M_{2}, M_{3}\right\}, M_{1}$ Self-built logistics, $M_{2}$ Logistics alliance, $M_{3}$ Outsourcing logistics。

\section{Step 2: Establish prior judgment matrix}

Matrix that is built based on the importance of lower factors to upper factors is called reciprocal judgment matrix. We choose to use three-demarcation method to compare the importance of two factors distinctly.

$$
f_{i j}=\left\{\begin{array}{cc}
1 & \text { facter } \mathrm{i} \text { is more important than } \mathrm{j} \\
0.5 & \text { facter } \mathrm{i} \text { is as important as } \mathrm{j} \\
0 & \text { facter } \mathrm{j} \text { is more important than } \mathrm{i}
\end{array}\right.
$$

$F=\left(f_{i j}\right)_{n \times n}$ is reciprocal judgment matrix. 
We should establish two kinds of reciprocal judgment matrixes between the target layer, criterion layer and solution layer because evaluation index hierarchy structure include three levels.

\section{Step 3: Transform reciprocal judgment matrixes into fuzzy consistent matrixes}

Solve row sum $r_{i}=\sum_{j=1}^{n} f_{i j}$. Use conversion formula $r_{i j}=\frac{r_{i}-r_{j}}{2 n}+0.5$ to transform reciprocal judgment matrixes $F=\left(f_{i j}\right)_{n \times n}$ to fuzzy consistent matrixes R.

\section{Step 4: Single hierarchical order}

$$
R=\left(r_{i j}\right)_{n \times n}=\left[\begin{array}{cccc}
r_{11} & r_{12} & \bullet & r_{1 n} \\
r_{21} & r_{22} & \bullet & r_{2 n} \\
\bullet & \bullet & \bullet & \bullet \\
r_{n 1} & r_{n 2} & \bullet & r_{n n}
\end{array}\right]
$$

Use fuzzy consistent judgment matrix to calculate the order of importance of various factors W. The weighted index normalized processing.

(1) Solve the sum of every row in fuzzy consistent matrixes, $l_{i}=\sum_{j=1}^{n} r_{i j}-0.5$

(2) Solve the sum of factors containing no diagonal elements, $\sum_{i} l_{i}=n(n-1) / 2, l_{i}$ means the importance of factor $i$ to upper factors.

(3) Get each index weight by normalization of $l_{i}$

$$
W_{i}=l_{i} / \sum l_{i}=2 l_{i} / m(m-1)
$$

\section{Step 5: Total hierarchical order}

Use the results of and the level of importance weights to get the total hierarchical order based on single hierarchical order. As a result, we can get the pros and cons of various options, excellent-inferior coefficient $T_{i}=\sum_{k=1}^{n} w_{k} W_{i}^{k} . \mathrm{T}$ is larger, the more optimal of solution.

\section{Conclusion}

At present, logistics operation modes that fit the development of China's e-commerce enterprise mainly have three kinds: self-built logistics mode, third party logistics mode and logistics alliance mode. E-commerce enterprises need a combination of specific logistics environment and their own development requirements. They should choose the logistics operation mode which is suitable for their own development by strength and business characteristics, strategic position of logistics, logistics management ability, existing logistics resources, developmental level of 3PL. In this paper, we use F-AHP to make objective and scientific evaluation on logistics operation modes based on evaluation index hierarchy structure.

\section{References}

[1] Danqing Du, Ruoxi Yu: Enterprise electronic commerce logistics mode selection method research [J]. E-commerce, 2010.11:50-53.

[2] Kent N Gourdin: Global Logistics Management-A Competitive Advantage for the New Millennium[M]. Blackwell Publishers Ltd,2001:218-230.

[3] Oliver E.Williamson: Transaction-Cost Economics:The Governance of Contractual Relations, The University of Chicago Press, Journal of Law and Economics, Vol. 22, No. 2 (Oct.1979), at 233-261. 